\begin{tabular}{|c|c|}
\hline Title & Structures of restriction endonuclease HindllI in complex with its cognate DNA and divalent cations \\
\hline Author(s) & W atanabe, Nobuhisa; Takasaki, Y ozo; Sato, Chika; A ndo, Shoji; Tanaka, Isao \\
\hline Citation & $\begin{array}{l}\text { A cta Crystall lographica. Section D, Biological Cry stal lography, 65(12), 1326-1333 } \\
\text { https://doi.org/10.1107/\$0907444909041134 }\end{array}$ \\
\hline Issue Date & $2009-12$ \\
\hline Doc URL & http:/hdl.handle.net/2115/39986 \\
\hline Type & article \\
\hline File Information & watanabe_A ctaCristD65.pdf \\
\hline
\end{tabular}

Instructions for use 
Acta Crystallographica Section D

Biological

Crystallography

ISSN 0907-4449

Editors: E. N. Baker and Z. Dauter

\title{
Structures of restriction endonuclease HindIII in complex with its cognate DNA and divalent cations
}

\author{
Nobuhisa Watanabe, Yozo Takasaki, Chika Sato, Shoji Ando and Isao \\ Tanaka
}

Acta Cryst. (2009). D65, 1326-1333

Copyright (C) International Union of Crystallography

Author(s) of this paper may load this reprint on their own web site or institutional repository provided that this cover page is retained. Republication of this article or its storage in electronic databases other than as specified above is not permitted without prior permission in writing from the IUCr.

For further information see http://journals.iucr.org/services/authorrights.html

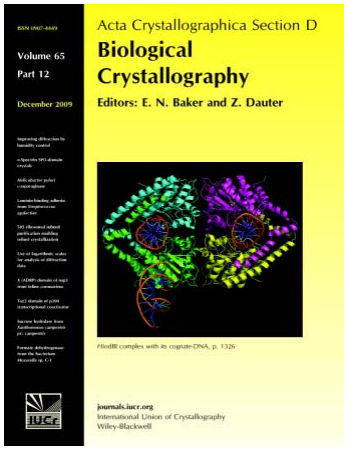

Acta Crystallographica Section D: Biological Crystallography welcomes the submission of papers covering any aspect of structural biology, with a particular emphasis on the structures of biological macromolecules and the methods used to determine them. Reports on new protein structures are particularly encouraged, as are structure-function papers that could include crystallographic binding studies, or structural analysis of mutants or other modified forms of a known protein structure. The key criterion is that such papers should present new insights into biology, chemistry or structure. Papers on crystallographic methods should be oriented towards biological crystallography, and may include new approaches to any aspect of structure determination or analysis.

Crystallography Journals Online is available from journals.iucr.org 
Acta Crystallographica Section D

Biological

Crystallography

ISSN 0907-4449

Nobuhisa Watanabe, ${ }^{a, b, c *}$

Yozo Takasaki, ${ }^{\text {d }}$ Chika Sato, ${ }^{c}$ Shoji Ando ${ }^{d}$ and Isao Tanaka

a Department of Biotechnology and Biomaterial Chemistry, Graduate School of Engineering,

Nagoya University, Japan, ${ }^{\mathbf{b}}$ Synchrotron

Radiation Research Center, Nagoya University, Japan, 'Division of Molecular Life Science, Faculty of Advanced Life Science, Hokkaido University, Japan, and ${ }^{\mathbf{d}}$ Faculty of Medicine,

Saga University, Japan

Correspondence e-mail: nobuhisa@nagoya-u.jp

\section{Structures of restriction endonuclease HindIII in complex with its cognate DNA and divalent cations}

The three-dimensional crystal structures of HindIII bound to its cognate DNA with and without divalent cations were solved at 2.17 and $2.00 \AA$ resolution, respectively. HindIII forms a dimer. The structures showed that HindIII belongs to the EcoRI-like ( $\alpha$-class) subfamily of type II restriction endonucleases. The cognate DNA-complex structures revealed the specific DNA-recognition mechanism of HindIII by which it recognizes the palindromic sequence A/AGCTT. In the $\mathrm{Mg}^{2+}$ ion-soaked structure the DNA was cleaved and two ions were bound at each active site, corresponding to the two-metal-ion mechanism.

\section{Introduction}

Restriction endonucleases are produced in bacteria, archaea and Chlorella viruses. These enzymes hydrolyze foreign DNA and thus allow microorganisms to avoid attack by phages etc. Based on subunit composition, cofactor requirements, DNArecognition specificity and mode of action, restriction endonucleases have been classified into four types (Roberts et al., 2003). Type II restriction endonucleases recognize and digest specific palindromic sequences of double-stranded DNA. About 4000 type II restriction endonucleases have been discovered to date. The specificity of the type II restriction endonucleases has made them indispensable tools in biotechnology. However, the tertiary structures of only about 30 type II restriction endonucleases are available at present in REBASE (Roberts et al., 2007). Most of the type II restriction endonucleases have a common sequence motif PD-(D/E) $x \mathrm{~K}$ (Stahl et al., 1998). Pingoud et al. (2005) showed that they contain a core comprised of a five-stranded mixed $\beta$-sheet flanked by $\alpha$-helices and that the second and third $\beta$-strands form a scaffold for the catalytic residues of $\mathrm{PD}-(\mathrm{D} / \mathrm{E}) x \mathrm{~K}$. Typically, type II restriction enzymes utilize $\mathrm{Mg}^{2+}$ ion as a divalent cation. Recent reviews have focused on their structure and function, the role of metal ions and their catalytic mechanisms (Pingoud \& Jeltsch, 2001; Pingoud et al., 2005).

The type II restriction endonuclease HindIII produced in Haemophilus influenzae Rd digests DNA at the palindromic sequence A/AGCTT. HindIII is comprised of 300 amino acids and has a molecular weight of $34950 \mathrm{Da}$. The amino-acid sequences of this nuclease and the corresponding methyltransferase were deduced from their genes (Nwankwo et $a l ., 1994)$. We have previously reported protein-engineering studies on HindIII (Tang et al., 2000). One mutant, D108L, showed a complete loss of enzyme activity, suggesting that
Received 13 July 2009

Accepted 8 October 2009

PDB References: HindIIIcognate DNA complex, 2e52, r2e52sf; metal-ion bound, $3 \mathrm{a} 4 \mathrm{k}, \mathrm{r} 3 \mathrm{a} 4 \mathrm{ksf}$. 
Table 1

Crystallographic data-collection and refinement statistics.

\begin{tabular}{llll}
\hline & Iodine derivative & Native & $\mathrm{Mg}^{2+}$-soaked $^{-}$ \\
\hline Beamline & BL-5A & NW-12A & BL-6A \\
Wavelength $(\AA)$ & 1.5 & 1.0 & 1.0 \\
Space group & $P 2_{1}$ & $P 2_{1}$ & $P 2_{1}$ \\
Unit-cell parameters $\left(\AA{ }^{\circ}\right)$ & $a=83.9, b=130.9$, & $a=83.1, b=131.5$, & $a=83.5, b=132.2$, \\
& \multicolumn{1}{c}{$c=93.6, \beta=110.2$} & $c=93.7, \beta=111.2$ & $c=94.1, \beta=111.0$ \\
Resolution $(\AA)$ & $2.77(2.87-2.77)$ & $2.00(2.07-2.00)$ & $2.17(2.25-2.17)$ \\
Unique reflections & 48465 & 130036 & 100664 \\
Redundancy & 3.6 & 7.6 & 1.9 \\
Completeness $(\%)$ & $95.3(67.4)$ & $99.9(99.5)$ & $99.8(98.0)$ \\
$R_{\text {merge }}(\%)$ & $9.2(37.4)$ & $5.6(14.3)$ & $5.4(40.4)$ \\
$I / \sigma(I)$ & $7.6(1.6)$ & $23.2(12.5)$ & $24.7(3.5)$ \\
Mosaicity $\left({ }^{\circ}\right)$ & 1.00 & 0.25 & 0.49 \\
Refinement resolution $(\AA)$ & & 2.00 & 2.17 \\
$R_{\text {work }} / R_{\text {free }}(5 \%$ of reflections) & & $17.7 / 21.7$ & $17.5 / 22.1$ \\
No. of waters & & 968 & 598 \\
R.m.s.d. bond lengths $(\AA)$ & & 0.015 & 0.02 \\
R.m.s.d. bond angles $\left({ }^{\circ}\right)$ & & 1.50 & 1.84 \\
Average $B$ factor $\left(\AA^{2}\right)$ & 23.8 & 36.1 \\
\hline
\end{tabular}

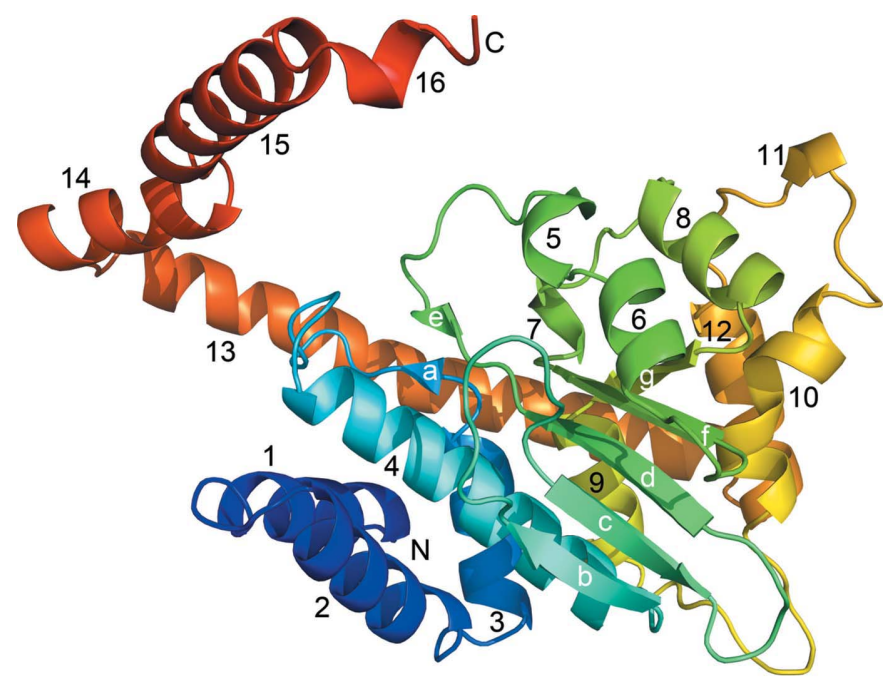

(a)

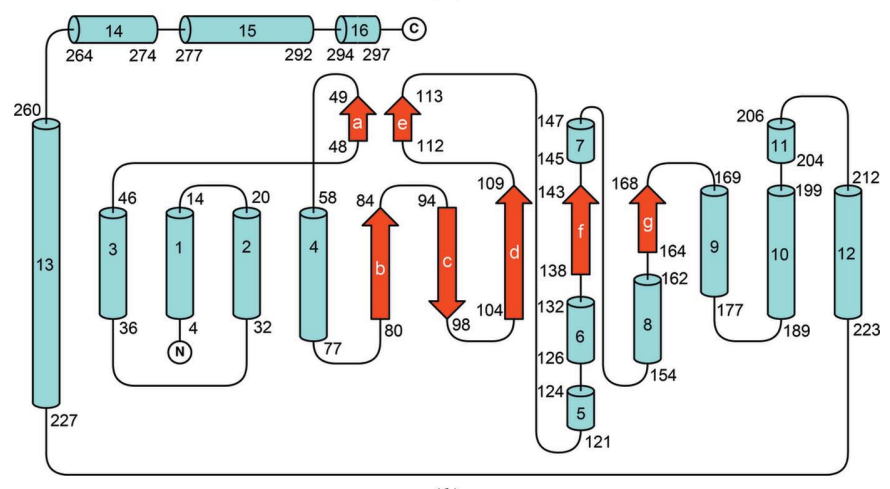

(b)

Figure 1

Overall structure of the HindIII monomer. (a) HindIII monomer with labelled helices and $\beta$-strands. (b) Topology diagram of HindIII. $\beta$-Sheets are shown in red and helices are shown in cyan.

Asp108 is located in the active site of the enzyme. We also found that the mutant E86K showed higher activity than the wild-type enzyme (Tang et al., 1999). However, the tertiary structure of HindIII has not been determined. To facilitate further studies of substrate recognition and enzyme catalysis, we have determined the HindIII crystal structure in its cognate DNA complex with and without metal ions.

\section{Materials and method}

\subsection{Protein purification and crystallization}

Wild-type HindIII was expressed in a His-tagged form (with ten His residues at the N-terminus). The HindIII protein was purified by a modification of the method reported previously (Tang et al., 2000). The HindIII-RM gene inserted into the pET16b vector was expressed in Escherichia coli BL21 (DE3) pLysS. The bacteria were grown in 31 LB medium containing $50 \mu \mathrm{g} \mathrm{ml}^{-1}$ ampicillin, harvested and sonicated to obtain crude extract. The extract in binding buffer ( $5 \mathrm{~m} M$ imidazole, $0.5 \mathrm{M}$ $\mathrm{NaCl}$ and $20 \mathrm{~m} M$ Tris- $\mathrm{HCl} \mathrm{pH}$ 8.0) was applied onto a column packed with His-Bind Resin (Novagen, San Diego, California, USA) in $50 \mathrm{mM} \mathrm{NiSO}$. The column was washed with binding buffer and then with wash buffer $(60 \mathrm{~m} M$ imidazole, $0.5 M$ $\mathrm{NaCl}$ and $20 \mathrm{~m} M$ Tris- $\mathrm{HCl} \mathrm{pH}$ 8.0). The protein was eluted by adding $0.05 M$ EDTA, $0.1 M$ EDTA, $0.1 M$ EDTA $+0.1 M$ imidazole, $0.1 M$ EDTA $+0.2 M$ imidazole, $0.1 M$ EDTA + $0.5 \mathrm{M}$ imidazole and then $1.0 \mathrm{M}$ imidazole to the column in a stepwise manner. HindIII protein eluted in the $0.1 M$ and $0.2 M$ imidazole fractions. The purified protein thus obtained was dialyzed against a buffer containing $20 \mathrm{~m} M$ Tris- $\mathrm{HCl} \mathrm{pH}$ 8.0 and $0.2 \mathrm{M} \mathrm{NaCl}$ overnight. Protease Xa was added to the sample to remove the His tag by treatment at $285 \mathrm{~K}$ for $14 \mathrm{~h}$. The sample was then added to the His-Bind resin column and the flowthrough fraction was collected and concentrated to $10 \mathrm{mg} \mathrm{ml}^{-1}$ with Amicon Ultra (Millipore, Billerica, Massachusetts). The weight ratio of protease Xa to HindIII was less than $0.1 \%$ and therefore no trace was observed in the concentrated sample.

DNA oligonucleotides (5'-GCCAAGCTTGGC-3') were synthesized and purified by HPLC (Hokkaido System Science, Sapporo, Japan). The oligonucleotides for use in crystallization trials were dissolved in Milli-Q reverse-osmose purified water. The oligonucleotide solution was heated to $368 \mathrm{~K}$ for $10 \mathrm{~min}$, followed by slow cooling to room temperature. Protein-DNA complexes were prepared by mixing annealed oligonucleotides with HindIII and incubating at $277 \mathrm{~K}$ overnight. The final protein-DNA complex solution contained HindIII protein at a concentration of $6.0 \mathrm{mg} \mathrm{ml}^{-1}$; the DNA duplex was present in a 1.5 -fold molar excess relative to the protein dimer.

Crystals of the HindIII-DNA complex were grown by the hanging-drop vapour-diffusion method over a reservoir of 12 16\%(v/v) PEG 3350, 80-120 mM ammonium acetate. Drops were formed by mixing $1 \mu$ l HindIII-DNA complex solution 
and $1 \mu \mathrm{l}$ reservoir solution and were equilibrated over the reservoir at $293 \mathrm{~K}$.

To elucidate the metal-binding structure of the HindIIIDNA complex, $\mathrm{Mg}^{2+}$ was introduced into the crystals of the HindIII-DNA complex using microdialysis buttons. The buttons were left in dialysis solution containing $20 \mathrm{mM} \mathrm{MgCl}$, $20 \%$ glycerol and reservoir solution for one week.

\subsection{Data collection}

The initial phases were determined at $2.8 \AA$ resolution by the SAD method using an iodinated derivative. Tyrosine residues in the HindIII-DNA complex crystals were iodinated using the vaporizing-iodine labelling method (Miyatake et al., 2006). The iodine SAD data were collected at $1.5 \AA$ wavelength and all other data sets were collected at $1.0 \AA$ wavelength using flash-frozen crystals at $95 \mathrm{~K}$. Native and iodinated crystals were cryoprotected with $20 \%(v / v)$ glycerol prior to cooling. All data sets were collected at the Photon Factory,

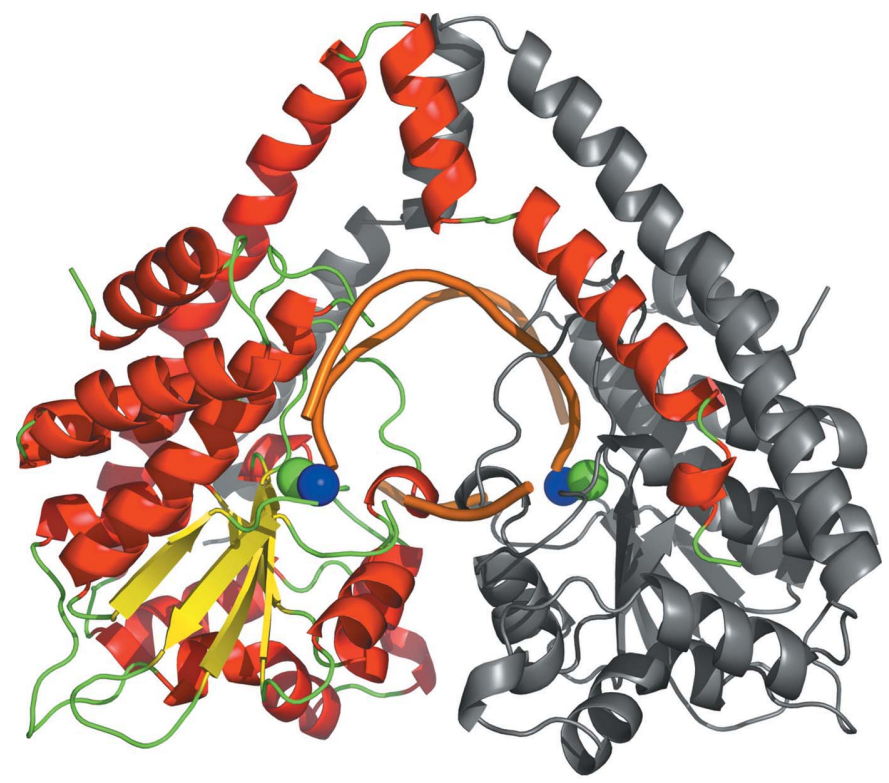

(a)

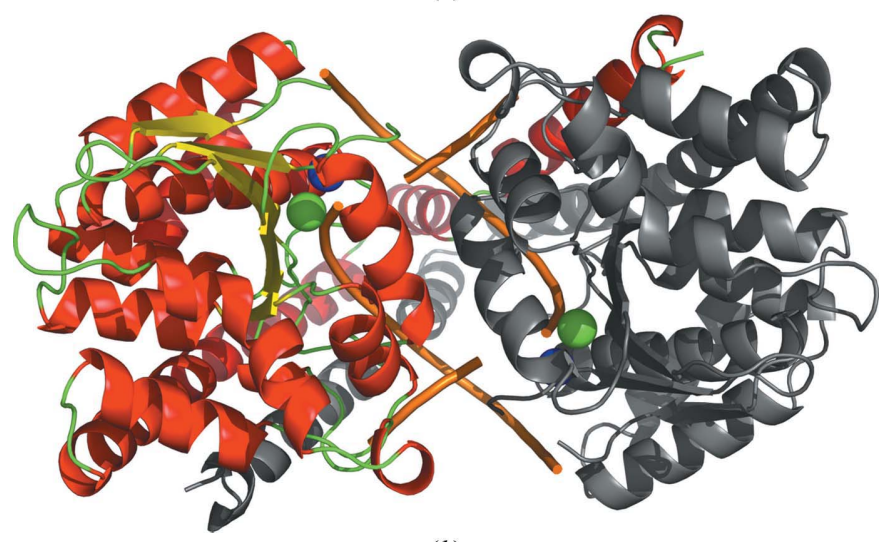

(b)

Figure 2

The dimer structure of the HindIII-DNA complex. (a) Top view of the complex. (b) View of the complex along the noncrystallographic dyad axis. The two metals observed in the $\mathrm{Mg}^{2+}$-soaked structure are also shown, with $\mathrm{Mg}^{2+}$ as blue spheres and $\mathrm{Mn}^{2+}$ as green spheres.
Tsukuba, Japan. Native, iodine-derivative and $\mathrm{Mg}^{2+}$ data sets were collected on beamlines NW12A, BL5A and BL6A, respectively. Diffraction data were processed using $H K L-2000$ (Otwinowski \& Minor, 1997).

\subsection{Structure solution and refinement}

Iodine positions were determined using $S H E L X C$ and SHELXD (Sheldrick, 2008) using the HKL2MAP interface (Pape \& Schneider, 2004); the iodine sites were refined and the initial SAD phases were calculated using the program SOLVE (Terwilliger \& Berendzen, 1999). Further phase improvement and auto model building were carried out using RESOLVE (Terwilliger, 2003a,b) and ARP/wARP (Perrakis et al., 1999). The structure of the HindIII-DNA complex was then refined with REFMAC5 (Murshudov et al., 1997) using $2.0 \AA$ resolution native data and manually fitted with Coot

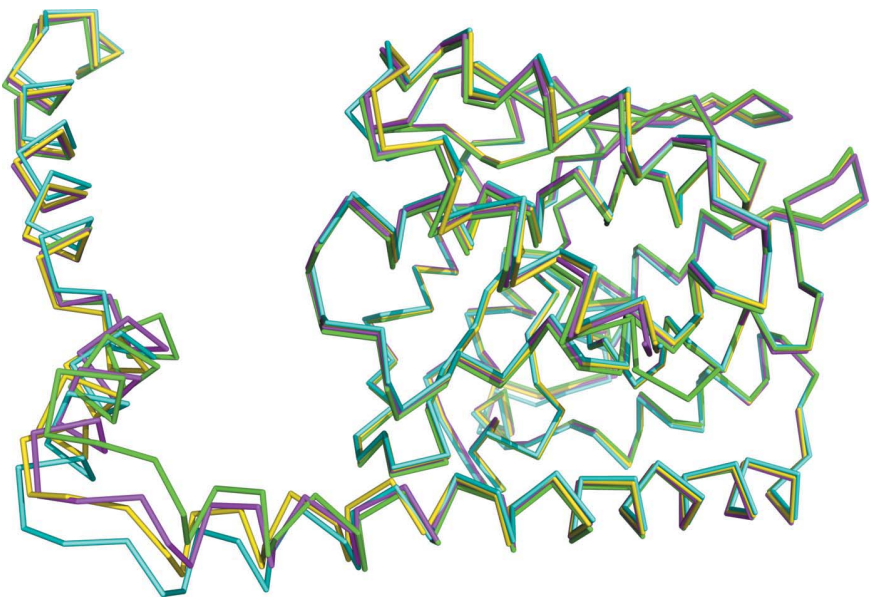

Figure 3

Superposition of the $\mathrm{C}^{\alpha}$ ribbons of the four monomers in the asymmetric unit. The monomers are coloured green $(A)$, cyan $(B)$, magenta $(C)$ and yellow $(D)$.

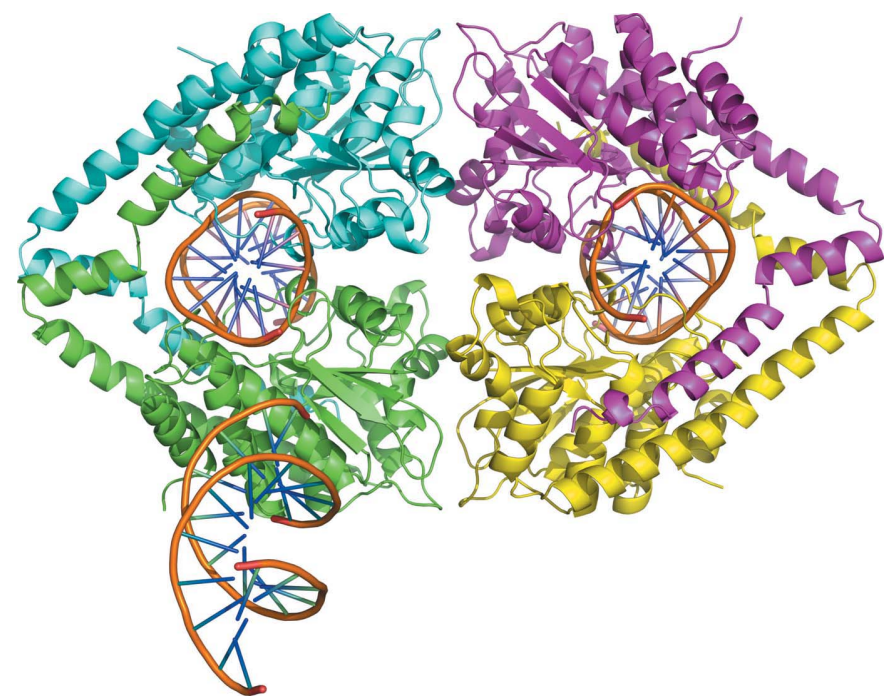

Figure 4

HindIII-DNA complex structure observed in the asymmetric unit. The four monomers are coloured green $(A)$, cyan $(B)$, magenta $(C)$ and yellow $(D)$. There is an extra free DNA duplex between monomer $A$ and monomer $B$ in the adjacent asymmetric unit. 


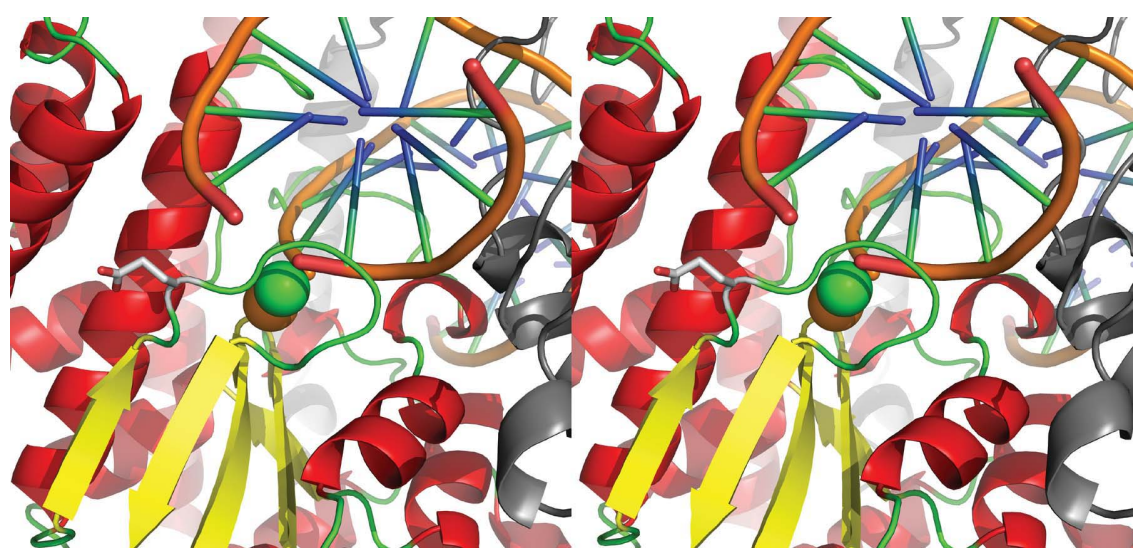

Figure 5

Stereo figure of the flexible-loop region of monomer $D$ of the metal-soaked structure. Grey helices are those of monomer $C$. The two metals $\mathrm{Mg}^{2+}$ and $\mathrm{Mn}^{2+}$ are shown as green and orange spheres, respectively. The side chain of Glu86 is shown as a stick model.
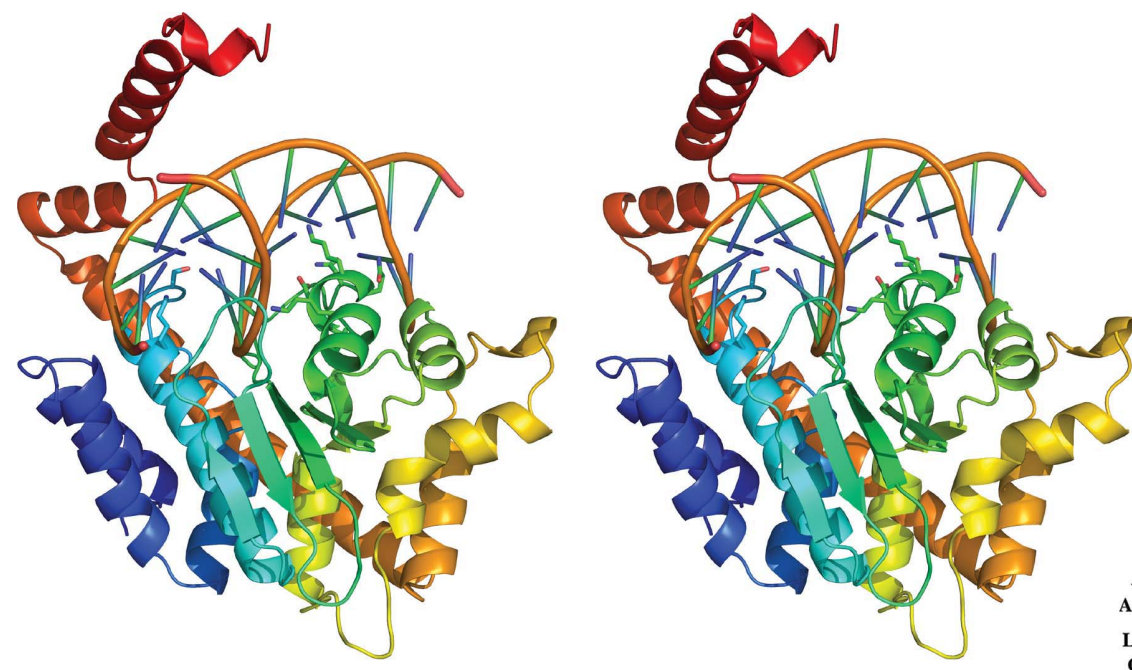

(a)

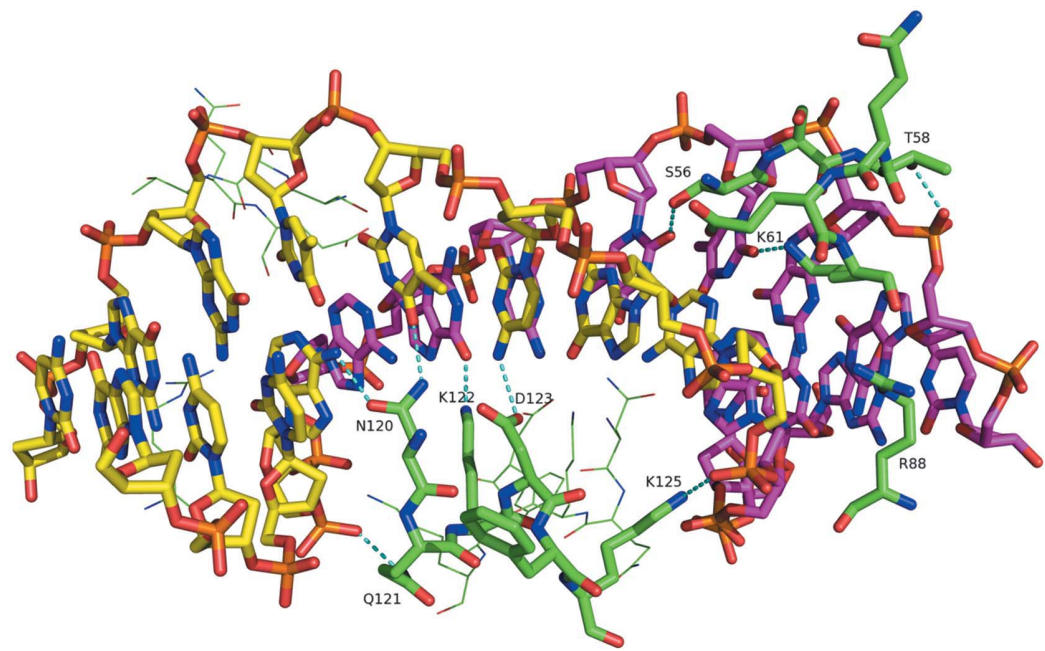

(b)
(Emsley \& Cowtan, 2004). Structures of the HindIII-DNA complex in the presence of $\mathrm{Mg}^{2+}$ ions were determined using the molecular-replacement program MOLREP (Vagin \& Teplyakov, 1997) using the HindIII-DNA complex as the molecular model.

Analysis of the stereochemical quality of the protein model and assignment of the secondary structure were performed with WHAT_CHECK (Hooft et al., 1996). Superposition of other restriction endonucleases was performed with $L S Q K A B$ (Kabsch, 1976) via CCP4i (Potterton et al., 2003). All figures were prepared using PyMOL (DeLano, 2002).

The final refinement statistics for the two structures are summarized in Table 1. Final coordinates were deposited in the Protein Data Bank with accession codes 2e52 and $3 \mathrm{a} 4 \mathrm{k}$ for the metal ion-free structure and the metal ion-bound structure, respectively.

Figure 6

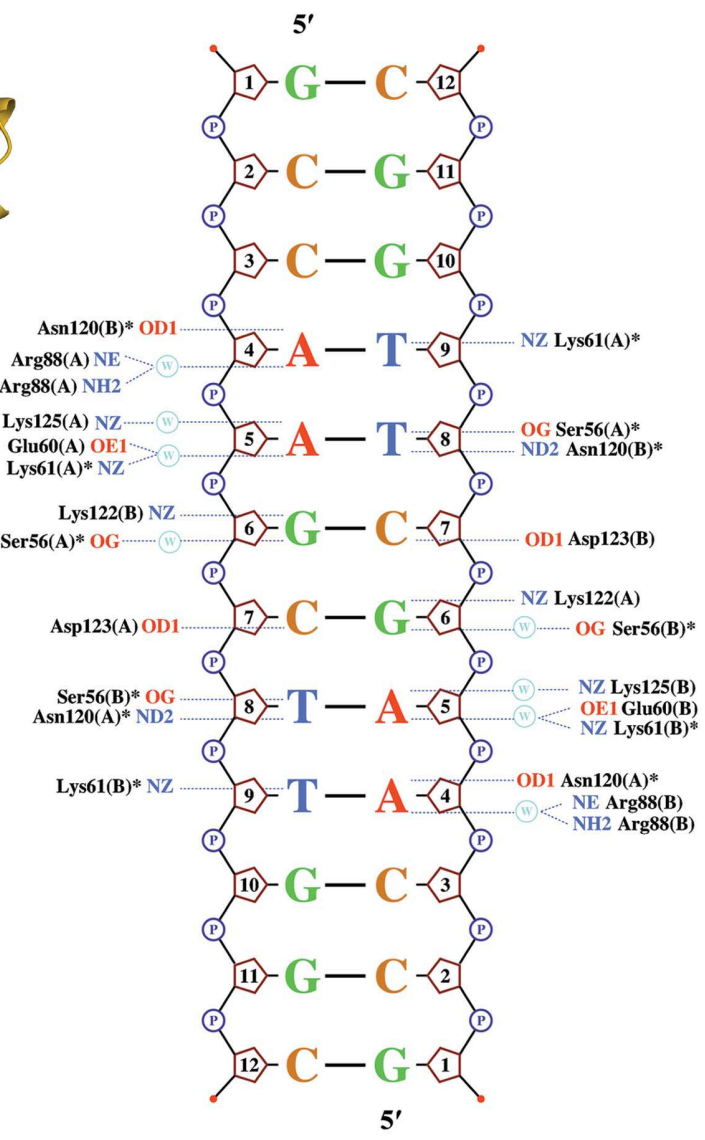

(c)

HindIII-DNA interactions. (a) Stereoview of the HindIII-DNA interaction. Only one monomer of HindIII is shown. Side chains with direct interactions to the bases are shown as stick models. (b) View of the base-pair recognition of HindIII, with hydrogen bonds indicated as dashed lines. The DNA is shown in yellow and magenta to indicate the two parts of the post-reaction product. (c) NUCPLOT sketch illustrating contacts between HindIII and the DNA bases. Contacts between HindIII AB dimer and the bases of the DNA strands $E$ and $G$ are shown. Asterisks indicate residues that appear more than once. 


\section{Results and discussion}

\subsection{Overall structure}

The HindIII monomer ( $35 \mathrm{kDa})$ consists of 16 helices and two $\beta$-sheets: one small sheet consisting of two short strands and a larger sheet comprised of five $\beta$-strands (Fig. 1). Helices 7,11 and 16 are $3_{10}$-helices. Helix 10 is a proline-kinked helix with Pro195 located near its centre. A $\beta$-sheet flanked by $\alpha$ helices is a core structure of restriction endonucleases (Venclovas et al., 1994). HindIII also has this core structure $(\alpha 4, \beta \mathrm{b}, \beta \mathrm{c}, \beta \mathrm{d}, \alpha 6, \beta \mathrm{f}, \alpha 8, \beta \mathrm{g}, \alpha 9)$. The three key residues of the canonical PD-(D/E) $x \mathrm{~K}$ catalytic motif, Asp108, Ala109 and Lys110, are located in this larger $\beta$-sheet. As $\beta \mathrm{g}$ is parallel to $\beta$ b, HindIII belongs to the EcoRI-like ( $\alpha$-class) subfamily (Venclovas et al., 1994; Pingoud \& Jeltsch, 1997; Kovall \& Matthews, 1999). Based on the classification of $\mathrm{Niv}$ and coworkers, HindIII belongs to class I, H1-S-H2-up, and H2 ( $\alpha 9$ in HindIII) is almost perpendicular to the $\beta$-strands (Niv et al., 2007).

The HindIII homodimer measures approximately $70 \times 80$ $\times 50 \AA$ (Fig. 2). The dimer formation of HindIII is interesting. The long arm consisting of the C-terminal four helices $(\alpha 13$, $\alpha 14, \alpha 15$ and $\alpha 16)$ protrudes from the core and interacts with its counterpart in the dimer. In particular, the long helix $\alpha 13$ and three helices $(\alpha 14, \alpha 15$ and $\alpha 16)$ of the adjacent monomer mainly make contact via hydrophobic interactions and form a hinge-like structure. Flexibility of the hinge can be observed when the structures of the four monomers in the asymmetric unit are superposed. The loop between $\alpha 13$ and $\alpha 14$ shows a displacement of more than $6.5 \AA$ (Fig. 3).

In the crystal, there are four protein monomers and three DNA duplexes in an asymmetric unit. The DNA strands are uncleaved in the cocrystal structure without metals. Protein subunits $A$ and $B$ or $C$ and $D$ form dimers which encircle double-stranded DNA molecules. In the asymmetric unit, the HindIII dimers form a tetramer with 222 symmetry (Fig. 4). Apart from the tetramer of the asymmetric unit, PISA (Krissinel \& Henrick, 2007) indicated that only the dimers are potentially biologically relevant, which is also consistent with the estimated molecular weight of the DNA complex on gelfiltration chromatography (data not shown). Interestingly, an extra DNA duplex, the occupancy of which was fixed to 0.7 in the final refinement cycles, exists like a 'shore' between the artificial tetramers. This extra DNA duplex may play an important supporting role in the crystal packing of this HindIII-DNA complex.

In the $\mathrm{Mg}^{2+}$-soaked structure eight metal peaks were found in the asymmetric unit, indicating two ions per active site. The DNA strands were cleaved in the crystal. No large structural changes were observed between the structures with and without cations. The overall structure of the HindIII-DNA complex was retained, but electron density in a loop between Leu85 and Gly89 was poor in monomers $A, B$ and $C$. Moreover, the Arg88 residues of these three monomers were completely disordered and their structures could not be built in the model. However, the electron density was clear for the $D$ chain and a model of the loop could be constructed with side chains. The loop conformation of the $D$ chain was almost the same as in the metal-free structure. As shown in Fig. 5, this loop is located near the active site, which it covers. Mutational analyses of HindIII showed that the E86K mutant had higher activity (Tang et al., 2000). The $k_{\text {cat }}$ of the E86K mutant was twice that of the wild type. As shown in the figure, Glu86 is located in the loop. The flexibility and charge distribution of this loop may be important in the transfer of metal ions and the mutation may affect the turnover of HindIII.

\subsection{Specific DNA recognition}

HindIII recognizes a specific 6 bp sequence with completely twofold symmetry. Contacts between HindIII and the bound DNA are shown in Figs. $6(a)$ and $6(b)$ and schematically in

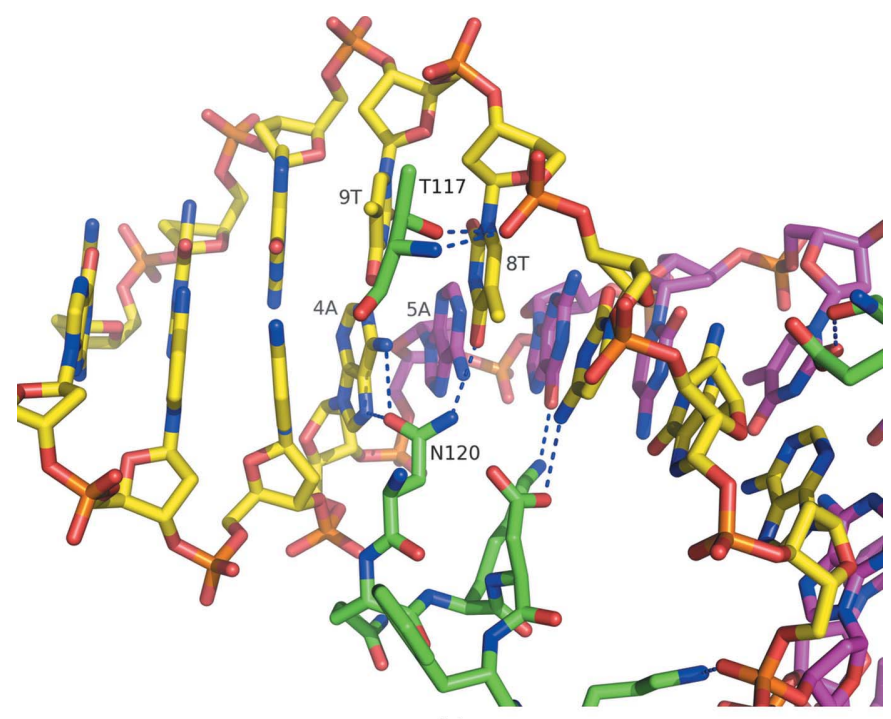

(a)

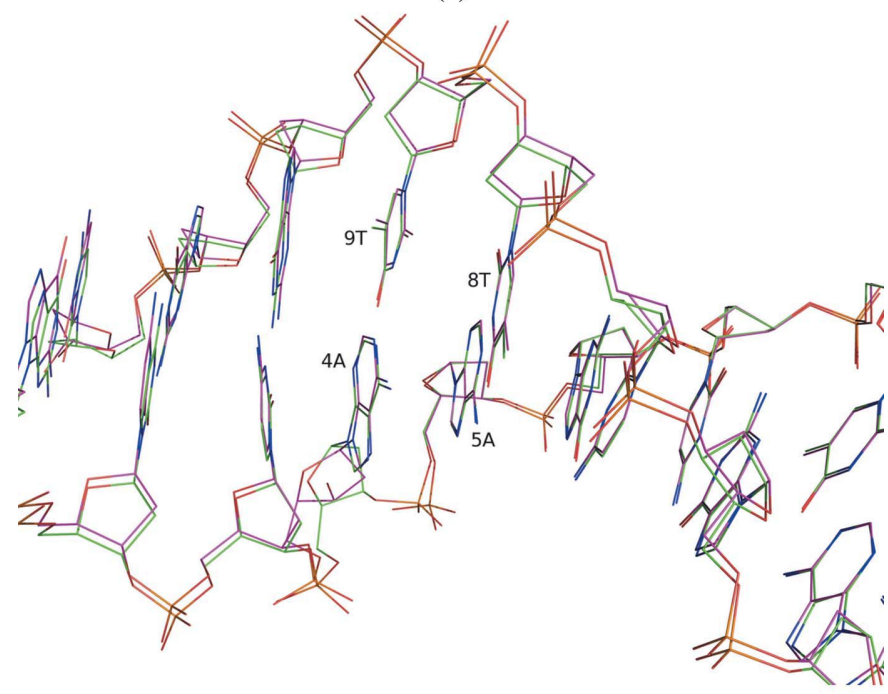

(b)

Figure 7

DNA structure near the scissile bond. (a) View of the HindIII-DNA interactions, with hydrogen bonds indicated as dotted lines. Residues of HindIII are coloured green and the DNA is shown in yellow and magenta to indicate the two parts of the post-reaction product. (b) Superposition of the DNA structures before and after the scission reaction. DNA before the reaction is shown in green and the cleaved DNA is shown in magenta. 
Fig. 6(c). The four residues that act at the major groove, Asp120, Lys122, Asp123 and Lys125, are on the short helix $\alpha 5$. Of the residues that act at the minor groove, Glu60 and Lys61 are located at the N-terminal end of helix $\alpha 4$, Ser56 is located in a loop between helices $\alpha 3$ and $\alpha 4$ and $\operatorname{Arg} 88$ is in the loop between the $\beta \mathrm{b}$ and $\beta \mathrm{c}$ strands. In the major groove, six direct

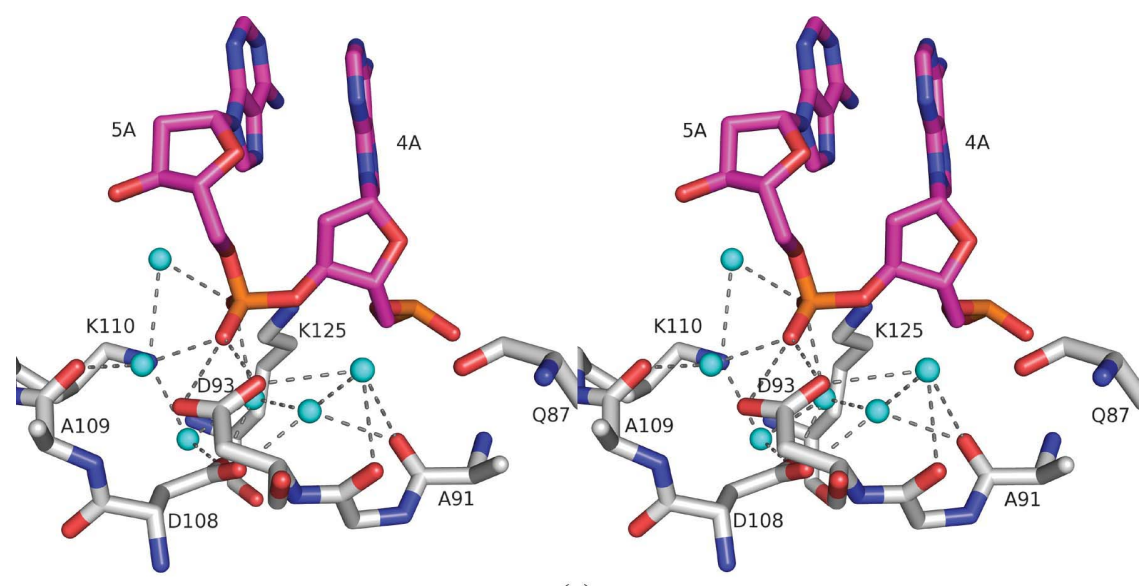

(a)

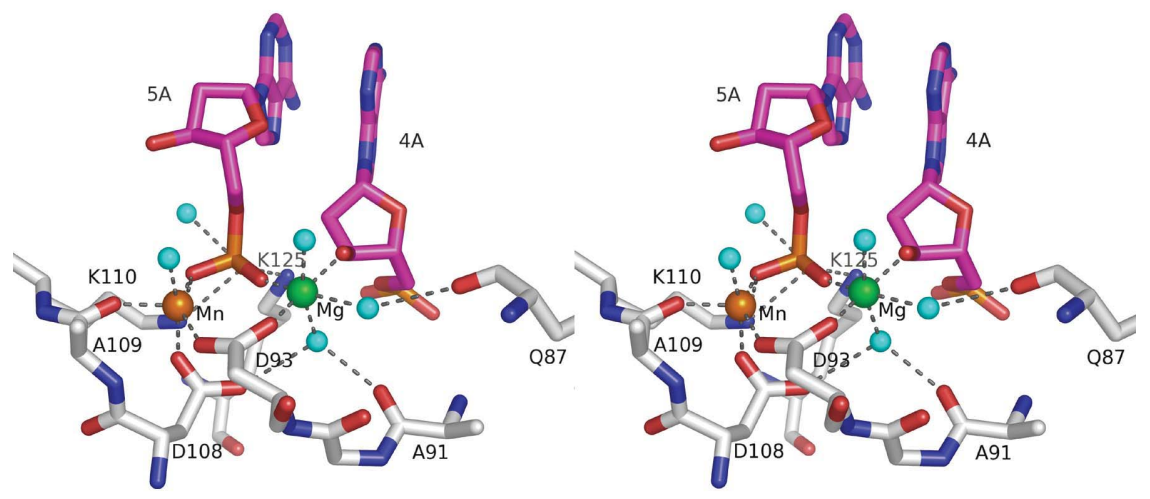

(b)
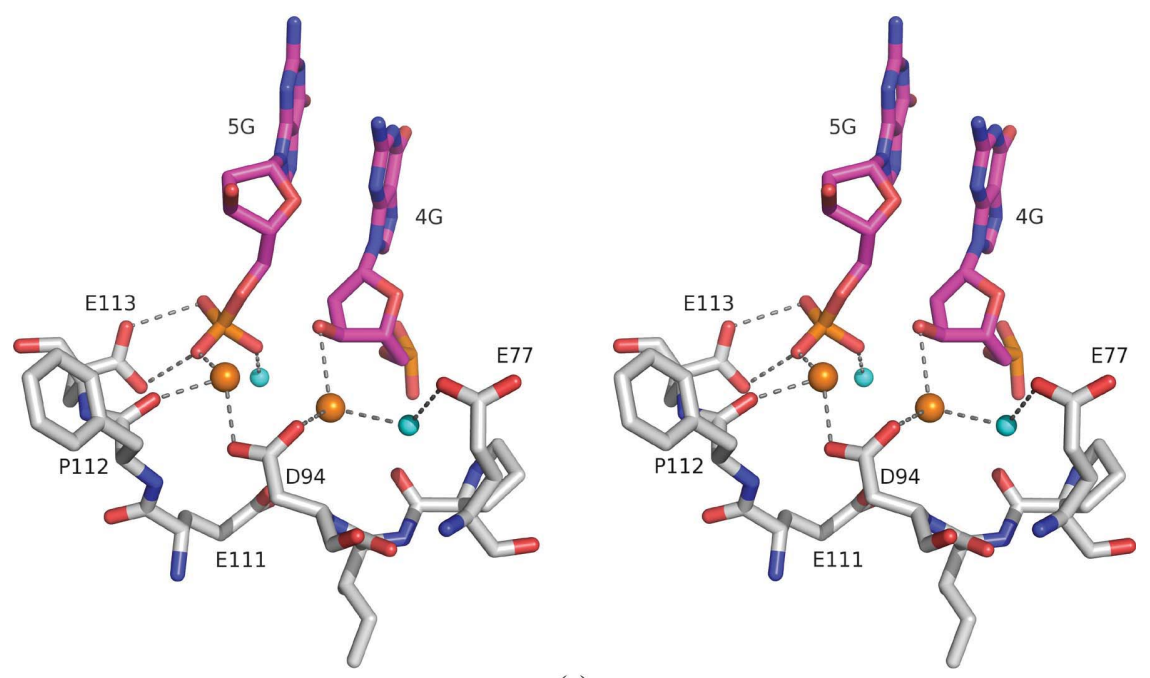

$(c)$

Figure 8

Active-site arrangement. (a) Stereoviews of the active site of the metal-free HindIII-DNA complex, $(b)$ of that of the $\mathrm{Mg}^{2+}$-soaked structure and $(c)$ of the active-site structure of BamHI. Water molecules are depicted as blue spheres and $\mathrm{Mg}^{2+}$ and $\mathrm{Mn}^{2+}$ are shown as green and orange spheres, respectively, with hydrogen bonds shown as dashed lines. hydrogen bonds and several water-mediated hydrogen bonds are formed between the protein and the bases of the specific sequence A/AGCTT of the DNA. Asn120 $\mathrm{O}^{\delta 1}$ forms a hydrogen bond to N6 of adenine 4A. Asn $120 \mathrm{~N}^{\delta}$ also makes contact with $\mathrm{O} 4$ of thymine $8 \mathrm{~T}$. Lys122 $\mathrm{N}^{\zeta}$ makes direct contact with $\mathrm{O} 6$ of guanine $6 \mathrm{G}$ and Asp123 $\mathrm{O}^{\delta 1}$ makes direct contact with $\mathrm{N} 4$ of cytosine $7 \mathrm{C}$. Lys125 $\mathrm{N}^{\zeta}$ forms a water-mediated hydrogen bond to $\mathrm{N} 7$ of adenine $5 \mathrm{~A}$. In the minor groove, two direct hydrogen bonds and three watermediated hydrogen bonds are formed to the specific bases. Lys61 $\mathrm{N}^{\zeta}$ makes direct contact with $\mathrm{N} 2$ of thymine 9T. Ser56 $\mathrm{O}^{\gamma}$ makes contact with $\mathrm{O} 2$ of thymine $8 \mathrm{~T}$. Contacts between $\operatorname{Arg} 88 \mathrm{~N}^{\eta 2}$ and $\mathrm{N}^{\varepsilon}$ and $\mathrm{N} 3$ of adenine 4A, between Lys61 $\mathrm{N}^{\zeta}$ and Glu60 $\mathrm{O}^{\varepsilon 1}$ and $\mathrm{N} 3$ of adenine $5 \mathrm{~A}$ and between Ser56 O ${ }^{\gamma}$ and N3 of guanine $6 \mathrm{G}$ are water-mediated. Direct interactions with the bases by HindIII are only formed to part of the specific sequence, with most occurring in the major groove. No direct contacts were identified using NUCPLOT (Luscombe et al., 1997) to the bases of the nonspecific sequence at both ends of recognition sequence, although there are many interactions between the sugar-phosphate backbone and the protein in this region, as observed for other endonucleases (Martin et al., 1999).

The conformation of the bound DNA is distorted from its ideal B-DNA structure. The overall amount of DNA distortion was about $57^{\circ}$ and that of shortening was about $8 \%$, while the DNA distortion and shortening of the extra free DNA found as a 'shore' between the artificial tetramers were $12^{\circ}$ and $0.6 \%$, respectively, as determined using the program CURVES (Lavery \& Sklenar, 1988). HindIII-DNA interactions and superposition of DNA structures around the scissile bond before and after the reaction are shown in Fig. 7. The overall DNA structures are almost the same, but the position of the ribose of adenosine $4 \mathrm{~A}$ is significantly shifted when the phosphate backbone is broken, even though the purine position does not change. As shown in the figure, interactions between Asn120 and adenine $4 \mathrm{~A}$ cause the purine to tilt about $25^{\circ}$ from the pyrimidine of its counterpart thymine 9T, resulting in an accumulation of strain in the DNA structure. In addition, Thr117, which forms hydrogen bonds to the backbone phosphate of thymine $8 \mathrm{~T}$, is the only residue in the disallowed region of the Ramachandran plot. 


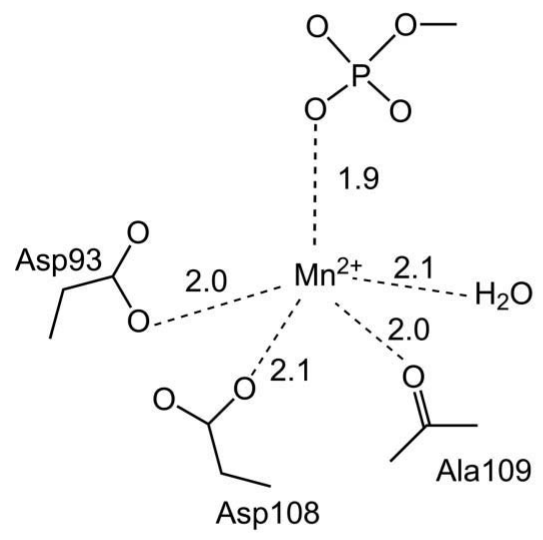

(a)

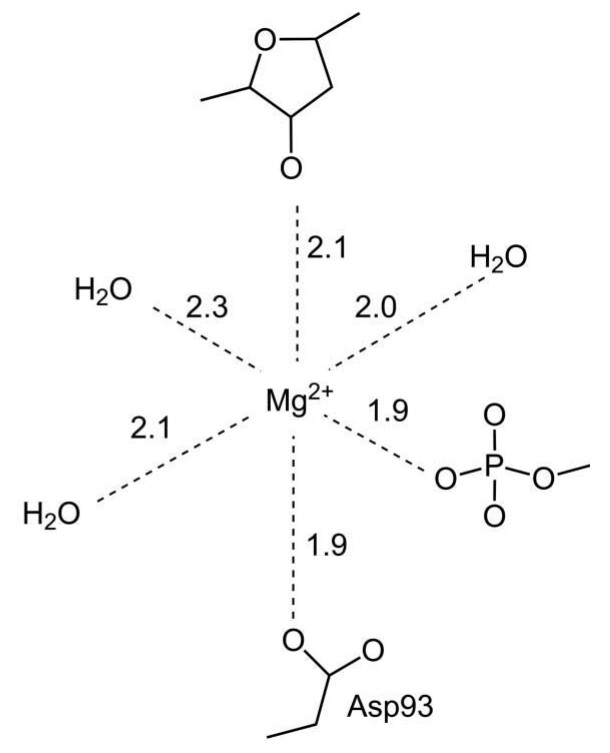

(b)

Figure 9

Diagrammatic representations of the metal ion-coordination geometries. $\mathrm{Mn}^{2+} \mathrm{A}$ site $(a)$ and $\mathrm{Mg}^{2+}$ B site $(b)$ are shown with the distances of each hydrogen bond.

Table 2

Refined temperature factors of the metal ions.

Refined $B$ factors of the A site are shown using $\mathrm{Mn}^{2+}$ and $\mathrm{Mg}^{2+}$ as the metal ions. Those of the B-site $\mathrm{Mg}^{2+}$ ions are also shown for comparison.

\begin{tabular}{|c|c|c|c|c|}
\hline \multirow[b]{2}{*}{ A site } & \multicolumn{2}{|c|}{ Refined $B$ factor $\left(\AA^{2}\right)$} & \multirow[b]{2}{*}{ B site } & \multirow[b]{2}{*}{ Refined $B$ factor $\left(\AA^{2}\right)$} \\
\hline & Using $\mathrm{Mn}^{2+}$ & Using $\mathrm{Mg}^{2+}$ & & \\
\hline$O$ & 27.05 & 7.34 & $S$ & 30.86 \\
\hline$P$ & 32.61 & 12.28 & $T$ & 34.80 \\
\hline$Q$ & 31.64 & 11.49 & $U$ & 37.11 \\
\hline$R$ & 33.98 & 13.34 & $V$ & 31.85 \\
\hline
\end{tabular}

\subsection{Active site}

In the $\mathrm{Mg}^{2+}$-soaked crystal two metal ions were found in the active site of each chain and the DNA was cleaved (Fig. 8). The presence of the two metal ions in the active centre of the $\mathrm{Mg}^{2+}$-soaked structure near the cleaved phosphate allowed us to unambiguously determine the catalytic mechanism of HindIII as the two-metal-ion mechanism (Beese et al., 1993; Viadiu \& Aggarwal, 1998). The distance between the two metal ions is $3.98 \AA$ and is consistent with the transition-state model of the two-metal-ion mechanism. Interestingly, the two metals seem to be different although the crystal was soaked with $\mathrm{Mg}^{2+}$. The metal ions located at the B site seemed to be $\mathrm{Mg}^{2+}$, but those at the A site were likely to be $\mathrm{Mn}^{2+}$. As we could not reproduce this high-resolution DNA-complex crystal, we were not able to confirm this using the anomalous signal of $\mathrm{Mn}^{2+}$ with longer wavelength X-rays, but the temperature factors of the refined metal sites suggested that the sites probably contained $\mathrm{Mn}^{2+}$ and not $\mathrm{Mg}^{2+}$ (Table 2). The temperature factor of the A-site metal tends to be lower than that of B site. For example, in the case of NgoMIV the $B$ factor of the A-site $\mathrm{Mg}^{2+}$ is $11.0-15.0 \AA^{2}$, while that of the B site is 22.0-31.0 $\AA^{2}$ (Deibert et al., 2000). For the HindIII structure, however, the temperature factors of the A-site metal ions are not consistent with those of the neighbouring atoms when using $\mathrm{Mg}^{2+}$ as the metal ion. As $\mathrm{MgCl}_{2}$ was used in the soaking experiment, the $\mathrm{Mn}^{2+}$ ion at the A site is probably the preferred selection by HindIII from the trace elements present. It is not clear why $\mathrm{Mn}^{2+}$ is preferred over $\mathrm{Mg}^{2+}$, but the difference in reaction kinetics between $\mathrm{Mn}^{2+}$ and $\mathrm{Mg}^{2+}$ in EcoRV has been discussed based on the intrinsic affinities of these ions for phosphates (Sam \& Perona, 1999) and seems to be consistent with the observation that the $\mathrm{Mn}^{2+}$ concentration optimum is about ten times lower than that of $\mathrm{Mg}^{2+}$ for many $\mathrm{PD}-(\mathrm{D} / \mathrm{E}) x \mathrm{~K}$-family endonucleases (Pingoud et al., 2009).

The geometry around the two metal ions is shown in Fig. 9. The A-site $\mathrm{Mn}^{2+}$ ion is pentacoordinated and the B-site $\mathrm{Mg}^{2+}$ ion is hexacoordinated. The coordination architecture of the two ions is as follows. Asp93 $\mathrm{O}^{\delta 1}, 5^{\prime}-\mathrm{O} 3 \mathrm{P}$ and $3^{\prime}-\mathrm{O} 3$ of cleaved DNA and three water molecules ligate the $\mathrm{B}$-site $\mathrm{Mg}^{2+}$ ion. Asp93 $\mathrm{O}^{\delta 2}$, Asp108 $\mathrm{O}^{\delta 2}$, the main-chain $\mathrm{O}$ atom of Ala109, 5'-O1P of cleaved DNA and one water molecule bind to the $\mathrm{Mn}^{2+}$ ion at the A site. The coordination distances are reasonable compared with the distributions in the MESPEUS database (Hsin et al., 2008). Asp93 of HindIII corresponds to Asp94 of BamHI, which is important for two-metal binding, as shown in Fig. 8. Our previous studies showed that another aspartic acid, Asp108, is also important for HindIII activity (Tang et al., 1999, 2000). As can be seen in Figs. 8(a) and 8(b), the conformation of Asp108 is changed to coordinate to the two metal ions and Asp108 interacts directly with $\mathrm{Mn}^{2+}$ at the A site and with $\mathrm{Mg}^{2+}$ at the $\mathrm{B}$ site by water-mediated hydrogen bonding.

In summary, we have presented the three-dimensional crystal structure of HindIII bound to cognate DNA in metalfree and $\mathrm{Mg}^{2+}$-soaked forms. The DNA was cleaved in the $\mathrm{Mg}^{2+}$-soaked form, indicating that the solved structure is the active form. Further studies are required as the metal ion at the A site is responsible for activating the nucleophile. However, other crystallization conditions are required that do not lead to the free extra DNA 'shore' between the artificial tetramers, as the present crystallization conditions were poorly reproducible.

This work was supported in part by the Takeda Science Foundation. The authors would like to thank Yukari Minami and Kaori Onishi for help with the crystallization of HindIII.

\section{References}

Beese, L. S., Friedman, J. M. \& Steitz, T. A. (1993). Biochemistry, 32, 14095-14101. 
Deibert, M., Grazulis, S., Sasnauskas, G., Siksnys, V. \& Huber, R. (2000). Nature Struct. Biol. 7, 792-799.

DeLano, W. L. (2002). PyMOL Molecular Viewer. DeLano Scientific, San Carlos, California, USA.

Emsley, P. \& Cowtan, K. (2004). Acta Cryst. D60, 2126-2132.

Hooft, R. W., Vriend, G., Sander, C. \& Abola, E. E. (1996). Nature (London), 381, 272.

Hsin, K., Sheng, Y., Harding, M. M., Taylor, P. \& Walkinshaw, M. D. (2008). J. Appl. Cryst. 41, 963-968.

Kabsch, W. (1976). Acta Cryst. A32, 922-923.

Kovall, R. A. \& Matthews, B. W. (1999). Curr. Opin. Chem. Biol. 3, 578-583.

Krissinel, E. \& Henrick, K. (2007). J. Mol. Biol. 372, 774-797.

Lavery, R. \& Sklenar, H. (1988). J. Biomol. Struct. Dyn. 6, 63-91.

Luscombe, N. M., Laskowski, R. A. \& Thornton, J. M. (1997). Nucleic Acids Res. 25, 4940-4945.

Martin, A. M., Sam, M. D., Reich, N. O. \& Perona, J. J. (1999). Nature Struct. Mol. Biol. 6, 269-277.

Miyatake, H., Hasegawa, T. \& Yamano, A. (2006). Acta Cryst. D62, 280-289.

Murshudov, G. N., Vagin, A. A. \& Dodson, E. J. (1997). Acta Cryst. D53, 240-255.

Niv, M. Y., Ripoll, D. R., Vila, J. A., Liwo, A., Vanamee, E. S., Aggarwal, A. K., Weinstein, H. \& Scheraga, H. A. (2007). Nucleic Acids Res. 35, 2227-2237.

Nwankwo, D. O., Moran, L. S., Slatko, B. E., Waite-Rees, P. A., Dorner, L. F., Benner, J. S. \& Wilson, G. G. (1994). Gene, 150, $75-80$.

Otwinowski, Z. \& Minor, W. (1997). Methods Enzymol. 276, 307-326.

Pape, T. \& Schneider, T. R. (2004). J. Appl. Cryst. 37, 843-844.
Perrakis, A., Morris, R. \& Lamzin, V. S. (1999). Nature Struct. Biol. 6, 458-463.

Pingoud, A., Fuxreiter, M., Pingoud, V. \& Wende, W. (2005). Cell. Mol. Life Sci 62, 685-707.

Pingoud, A. \& Jeltsch, A. (1997). Eur. J. Biochem. 246, 1-22.

Pingoud, A. \& Jeltsch, A. (2001). Nucleic Acids Res. 29, 37053727.

Pingoud, V., Wende, W., Friedhoff, P., Reuter, M., Alves, J., Jeltsch, A., Mones, L., Fuxreiter, M. \& Pingoud, A. (2009). J. Mol. Biol. 393, 140-160.

Potterton, E., Briggs, P., Turkenburg, M. \& Dodson, E. (2003). Acta Cryst. D59, 1131-1137.

Roberts, R. J. et al. (2003). Nucleic Acids Res. 31, 1805-1812.

Roberts, R. J., Vincze, T., Posfai, J. \& Macelis, D. (2007). Nucleic Acids Res. 35, D269-D270.

Sam, M. D. \& Perona, J. J. (1999). J. Am. Chem. Soc. 121, 1444-1447. Sheldrick, G. M. (2008). Acta Cryst. A64, 112-122.

Stahl, F., Wende, W., Jeltsch, A. \& Pingoud, A. (1998). Biol. Chem. 379, 467-473.

Tang, D., Ando, S., Takasaki, Y. \& Tadano, J. (1999). Biosci. Biotechnol. Biochem. 63, 1703-1707.

Tang, D., Ando, S., Takasaki, Y. \& Tadano, J. (2000). Protein Eng. 13, 283-289.

Terwilliger, T. C. (2003a). Acta Cryst. D59, 38-44.

Terwilliger, T. C. (2003b). Acta Cryst. D59, 45-49.

Terwilliger, T. C. \& Berendzen, J. (1999). Acta Cryst. D55, 849-861.

Vagin, A. \& Teplyakov, A. (1997). J. Appl. Cryst. 30, 1022-1025.

Venclovas, C., Timinskas, A. \& Siksnys, V. (1994). Proteins, 20, 279-282.

Viadiu, H. \& Aggarwal, A. K. (1998). Nature Struct. Biol. 5, 910-916. 